\title{
Technical Efficiency of Barley Production: The Case of Smallholde Farmers in Meket District, Amhara National Regional State, Ethiopia
}

Getachew Wollie

Samara University, Department of Economics

Email address for corresponding author; getachewwollie53@gmail.com

\begin{abstract}
This study analyzed the technical efficiency of barley production by smallholder farmers in Meket district, Amhara National Regional State, Ethiopia. A cross sectional data from a sample of 123 barley producers during the 2016/17 production season was collected by applying two stage random sampling. To address the objective of the study, both descriptive statistics and econometric models were used to analyze the data. The trans-log functional form of the production function simultaneously with single stage estimation approach was used to estimate the production of barley output and technical inefficiency factors. The estimated stochastic production frontier model indicated that input variables such as fertilizer, human labor and oxen power were the significant variables to increase the quantity of barley output while, barley seed had a negative effect. The estimated mean levels of technical efficiency of the sample farmers were about $70.9 \%$ which revealed that, presence of a room to increase their technical efficiency level on average by $29.1 \%$ with the existing resources. The discrepancy ratio gamma indicated that $63 \%$ of the total variation from the frontier comes due to technical inefficiency while, the remaining $37 \%$ comes due to factors outside the control of farmers. Among the hypothesized factors that affect technical inefficiency; education level, extension contact and number of barley plots significantly and negatively affected technical inefficiency score. Besides, practice of crop rotation, distance of residence from the nearest main market, total expenditure and soil fertility was found to have a positive and significant effect. Hence, emphasis should be given to decrease the inefficiency level of those more inefficient farm households via experience sharing among the farmers and usage of improved or certified barley seed. Besides to this, policies and strategies of the government should be directed towards increasing farmers' education, improve the system of input distributions and institutional facilities.
\end{abstract}

Keywords: Technical Efficiency; Stochastic Frontier; Trans-log; Meket; Barley 


\section{INTRODUCTION}

Ethiopia is ranked $21^{\text {th }}$ in the world in terms of barley production with a share of $1.2 \%$ of the world's total production and the second largest barley producer in Africa, next to Morocco and followed by Algeria, accounting about $25 \%$ of the total barley production in the continent (Abu and Teddy, 2014; FAO, 2014). Ethiopia is not only the largest producer but also the biggest consumer of barley in Africa. At the national level, barley accounts for about $5.6 \%$ of the per capita calorie consumption as a main ingredient in staple foods and local drinks. Hence, in relation to its dynamic nature and wide range of uses, barley is known as the "king of grains". Unlike in industrialized countries where barley is mainly used for animal feed and malting, barley is important for developing countries in terms of the lives and livelihood of smallholder farmers. It also a substitutable crop for other cereals in the country and serve as a roof thatch for many highlanders. (Berhane et al., 2011; CSA, 2014).

At the national level from the total area of cereals allocated in hectare, barley covered only $14.65 \%$ producing $13.37 \%$ quintals with the yield of 10.42 quintal per hectare. The total yield of barley has been increased by $4.99 \%$ between 2013/14 and 2014/15 and also by 5.2\% to the year 2015/16 (CSA, 2016). Furthermore, among the major cereals, barley is found to have experienced the highest annual fluctuation in area and yield. Hence, this fluctuation in barley yield and area shows that barley has received far less attention compared to the other major cereals, especially teff, maize and wheat (Shahidur et al., 2015).

Rapid population growth multiplies the problems concerning food and other fundamental human needs. Increasing food production is itself a complex process involving more intensive and extensive use of land and water, increased availability of basic agricultural inputs, appropriate agricultural policies and rural institutions and strengthened agricultural researches. However, if effort is made, the potential for increasing food production in every country in the world would be substantial. But, there is still yield gap between the output obtained from research stations and farmer's field. There are several factors believed to contribute to the low yield including moistures stress, shortage of seeds for improved varieties, degradation of soil fertility, insect pests, diseases, weeds and birds (Aung, 2012). This higher gap between yields of crops under farmer's management and what it can be obtained from on research farm clearly indicated that farmers has an opportunity to narrow 
this gap by increasing their crop production and earn higher yield as much as possible equal to the yield obtained at a research farm.

In Meket district, Barley is a major stable food and it takes the lion share in terms of the extent of production, food consumption, number of producers and area coverage relative to other major cereals grown in the district but, its production was owned by small holder farmers which produces only to survive their hand to mouth livelihood. Therefore, it is crucial to increase their volume of production and efficiency at least to secure their food needs at family level.

There are different empirical studies which were employed within Ethiopia and abroad in different agro-climatic and socio-economic conditions indicated the existence of efficiency differentials among small-scale farmers at different time period. Moreover, the findings or conclusions of some of them are not consistent with one another because of, different agro ecological nature, farming system, and other factors. Therefore, policy implications drawn from those empirical works also may not allow in designing area specific policies to be compatible with its socio-economic as well as agro-ecologic conditions. Hence, this study intends to fill these gaps by having the general objective of this study was to analyze the economic efficiency of barley production the case of smallholder farmers in Meket district, Amhara National Regional State, Ethiopia. The specific objectives of the study were also to estimate the level of technical efficiency of small holder barley producers and to identify the determinants for variation of inefficiency of barley producers in Meket district.

\section{METHODOLOGIES}

\section{Study areas}

Meket district is one of the eleven districts in North Wollo zone of Amhara National Regional State, Ethiopia which is located $600 \mathrm{~km}$ north of Addis Ababa and bordered on the south by Wadla districts, on the west by Debub Gondar Zone, on the northwest by Bugna districts, on the north by Lasta, on the northeast by the Gidan districts and on the east by GubaLafto districts. There are four main agro-climatic zones in the district. These are the semiarid lowlands less than 2,300 masl, the sub-humid midlands from 2,300 to 2,800 masl, the humid highlands 2,800 to 3,200 masl, and the very-humid high altitude plateau, which is 
over 3,200 masl, is often battered by frost and hail. Currently, the total population of Meket has been reached to 263,567 of them $51.67 \%$ were male and that of $48.33 \%$ were females.

\section{Sampling Technique and sample size}

The sampling technique employed in this study was two-stage sampling technique. Meket districts has a major barley producers and large extent of production in the zone. From the total 47 kebeles of Meket district only 21 kebeles produce barley. In the first stage, a total of three sample kebeles from 21 barley producer kebeles in the district were randomly selected. In the second stage, 123 sample farmers were selected by using simple random sampling technique from each kebele based on probability proportional to size.

The sample size of farmers was determined by applying Yamane's (1967) formula of calculating sample size with confidence interval of $95 \%$ and variability 0.05 .

$n=\frac{N}{1+N(e)^{2}}$

Where: $\mathrm{n}=$ the sample size, $\mathrm{N}=$ number of barley producer households in Meket district in 2015/16 production season (which is 18036), e= margin of error (which equals with 9\%) then, $\mathrm{n}=122.6$ but, the sample size held in this study was 123 .

Both primary and secondary data were used for this study. Primary data were collected from a cross sectional sample representative 123 farm households from three rural kebele's through questionnaires. Secondary data also collected from different governmental and nongovernmental institutions including both published and unpublished documents at zonal and district level regarding the baseline general information to support the primary data.

\section{Method of Data Analysis}

Descriptive statistics and econometric models were employed to achieve the objective of the study. The descriptive statistics includes means, standard deviation, minimum, maximum, frequencies and percentage. Regarding the econometric model, different tests of hypothesis were considered to select the appropriate functional form and model which can fit to the data set. After conducting all the required hypothesis and make decision, a transcendental logarithmic functional form simultaneously with one stage estimation procedure of frontier model was used to analyze technical inefficiency variables. 
The output of barley was modeling in terms of five major input variables namely, amount of fertilizer, amount of human labor, quantity of seeds, oxen power and land allocated for barley crop. The transcendental logarithmic functional forms of the production function were expressed as;

$Y=F(X \beta) \exp \varepsilon$

Where, $Y=$ barley output, $X_{i}=$ vector of input quantities, $\beta i=$ a vector parameters to be estimated and $\varepsilon=$ composed error consisting of element $\mathrm{U}$ and $\mathrm{V}$,

The random disturbance term $V_{i}$ captures the effects of statistical noise on observed output outside the farmers control including measurement errors, climate change, topography, soil type, and others while, the stochastic noise $U_{i}>0$ is included to capture effects from technical inefficiency. Hence, both $\mathrm{U}$ and $\mathrm{V}$ are independent of each other (Aigner et al., 1977).

According to Aigner et al. (1977), the advantage of this approach is we can estimate the variance of $\mathrm{V}_{\mathrm{i}}$ and $\mathrm{U}_{\mathrm{i}}$, productive efficiency should be measured by the ratio of $\frac{Y_{i}}{\left[F\left(X_{i} ; \beta\right)+V_{i}\right]}$ rather than by the ratio of $\frac{Y_{i}}{F\left(X_{i} ; \beta\right)}$ and lastly it distinguish productive inefficiency from other source of disturbances that are beyond the farmers control. The implicit trans-log form of the stochastic frontier production model was specified as follows;

$\ln Y_{i}=\ln \beta_{0}+\sum_{i=1}^{20} \beta_{i} * \ln x_{i k}+\frac{1}{2} \sum_{i=1}^{20} \sum_{j=1}^{20} \beta_{i j} * \ln x_{i k} * \ln x_{j k}+\varepsilon_{i}$

$\ln Y_{i}=\beta_{0}+\beta_{1} \ln X_{1 i}+\beta_{2} \ln X_{2 i}+\beta_{3} \ln X_{3 i}+\beta_{4} \ln X_{4 i}+\beta_{5} \ln X_{5 i}+\beta_{6} \ln X_{6 i}+\beta_{7} \ln X_{7 i}+$ $\beta_{8} \ln X_{8 i}+\beta_{9} \ln X_{9 i}+\beta_{10} \ln X_{10 i}+\beta_{11} \ln X_{11 i}+\beta_{12} \ln X_{12 i}+\beta_{13} \ln X_{13 i}+\beta_{14} \ln X_{14 i}+$ $\beta_{15} \ln X_{15 i}+\beta_{16} \ln X_{16 i}+\beta_{17} \ln X_{17 i}+\beta_{18} \ln X_{18 i}+\beta_{19} \ln X_{19 i}+\beta_{20} \ln X_{20 i}+\varepsilon$

Where, $L n=L o g a r i t h m$ to base e, $\beta i=$ the unknown parameters estimated, $i=1,2,3 \ldots n^{\text {th }}$ farmer, $\mathrm{j}$ =inputs of production used, $\mathrm{Y}_{\mathrm{i}}=$ Output of barley, $\mathrm{X}_{1}=$ Land allocated for barley crop (ha), $\mathrm{X}_{2}=$ Labor power (man-days), $\mathrm{X}_{3}=$ Amount of barley seeds used (kg), $\mathrm{X}_{4}=$ Oxen power (oxen days), $\mathrm{X}_{5}=$ Quantity of fertilizer used in barley crop $(\mathrm{kg})$, from $\mathrm{X}_{6}$ to $\mathrm{X}_{20}$ are the Square and interaction terms of those major five inputs, $\varepsilon=$ Random composed errorterm $(\mathrm{V}-\mathrm{U})$ and $\mathrm{n}=$ sample size 
Technical inefficiency scores were estimated on hypothesized farm related, socioeconomic and institutional factors using a one stage estimation procedure in frontier model simultaneously with the production function. The technical inefficiency model was specified as using:

$Y_{i}=f\left(\beta_{i} ; x_{i}\right)+v_{i}-\left(\delta_{i} z_{i}\right)$

Where, $\mathrm{Y}_{\mathrm{i}}$ is barley output and $\mathrm{Z}_{\mathrm{i}}$ is different farm specific, socioeconomic and institutional variables that affect technical inefficiency.

$Z_{i}=\alpha_{0}+\alpha_{1} p_{1 i}+\alpha_{2} p_{2 i}+\alpha_{3} p_{3 i}+\alpha_{4} \ln p_{4 i}+\alpha_{5} p_{5 i}+\alpha_{6} \ln p_{6 i}+\alpha_{7} p_{7 i}+\alpha_{8} p_{8 i}+\alpha_{9} p_{9 i}+$

$\alpha_{10} p_{10 i}+\alpha_{11} p_{11 i}+\alpha_{12} p_{12 i}+\alpha_{13} p_{13 i}+\varepsilon_{i}$

Where $\mathrm{Y}^{*}=$ Technical inefficiency ratio, $\mathrm{P} 1=$ Farming experiences of farmers in barley production (years), P2 = Farmer education level (years of schooling), P3 = Frequency of extension contact (numbers), P4 = Amount of credit taken (Ethiopian birr), P5 = Number of barley plots (number), P6 = Total expenditure of households (Ethiopian birr), P7 = Crop rotation $(0=$ if they practice crop rotation, 1 otherwise), P8 = Participation on non-farm income $(0=$ if yes and $=1$ if no), P9 = Livestock holding (TLU), P10= Fertility status of the soil ( $0=$ fertile, $1=$ otherwise), P11= Distance to market (kilometers), P12= Gender ( 0 if the household headed are male and 1 other wise) and P13=Distance of the plot from farmers home (walking minutes)

\section{RESULTS AND DISCUSSIONS}

\section{Descriptive Results about Barley output and input usage}

Output of barley was the dependent variable in the production function and estimated mainly with five important inputs which are fertilizer, seed, labor, oxen power and land that employed on the study area. The mean of barley output for the sample household in the study area in the 2015/16 production season was relatively 17 quintal with a minimum of 4 quintal to a maximum of 45 quintals. Generally, the average inorganic fertilizer application for the production of barley among the respondent was 40.52 kilogram and allocated 1.49 hectare of their farm plot for barley production. The sample households apply only local barley seed with an average of nearly 83.5 kilogram which was lower than the forecasting way of recommended barley seed rate (120 kilogram /hectare). On average, a total of 54.1 man days and 35 oxen days were needed for performing all related activities of farming in man days. 
Table 1. Summary of barley outputs with major five inputs

\begin{tabular}{lllll}
\hline Variable & Mean & Standard Deviation & Minimum & Maximum \\
\hline Output(quintal) & 16.94 & 9.22 & 4 & 45 \\
Fertilizer amount (kg) & 40.52 & 32.35 & 0 & 200 \\
Seed amount (kg) & 83.47 & 40.44 & 18 & 180 \\
Human labor (MDs) & 54.1 & 16.31 & 20 & 80 \\
Oxen power (ODs) & 34.88 & 8.91 & 20 & 50 \\
Land under barley (ha) & 1.49 & 0.78 & 0.25 & 5 \\
\hline
\end{tabular}

Source: Own computation (2017)

The mean education level of the sample household in the study area was 2.54 ranging from 0 to grade 10 . The mean frequency of extension contact was relatively nine times with a minimum of twice to a maximum of 18 times per barley production season. The average farming experience of the sample farmers in barley production were 33.62 years with a minimum of 5 years to that of a maximum of 62 years. It was also found that, the mean number of plots allocated for barley crop was 2.21 located at maximum of 4 plots in different location or site. In addition, on average a farmers must walk relatively one hour to reach on their farm plot. On average livestock population of the sample household farmers measured in tropical livestock unit was 3.29 with a minimum of 0.815 to a maximum of 15 . The mean total expenditure of the sample households was 1279.92 birr within the range of 300 birr and 5000 birr. The mean amount of credit obtained from different sources was 1775.61 birr ranging from null to 7000 birr. The mean distances of the nearest market to the farmers was $5.31 \mathrm{~km}$ and is ranging between $2 \mathrm{~km}$ and $12 \mathrm{~km}$.

Sample respondents were composed of both male and female household heads. Out of the total sampled household head farmers about $80.49 \%$ were male headed and the remaining $19.51 \%$ were female headed households. As it was presented in Table (5), 19.51\% of the sample households were not practicing crop rotation while, the remaining $80.49 \%$ was adopted the practice of crop rotation. Based on their perceptions, about $24.39 \%$ of the respondents classified the fertility status of their barley plot on average as infertile class while, $75.61 \%$ respondents graded it as fertile. The same table also told that, majority (which is $58.54 \%$ ) of the farmers had participated on different non-farm income activities while about $41.46 \%$ were had not any source of non-farm income. 
Table 2. Summary of variables that affect technical inefficiency

\begin{tabular}{|c|c|c|c|c|}
\hline Variables & Mean & $\begin{array}{l}\text { Standard } \\
\text { Deviation }\end{array}$ & $\begin{array}{l}\text { Percentage of the } \\
\text { mean with dummy } 0\end{array}$ & $\begin{array}{l}\text { Percentage of the } \\
\text { mean with dummy } 1\end{array}$ \\
\hline Level of education & 2.54 & 3.02 & & \\
\hline Extension contact & 9.31 & 3.14 & & \\
\hline Farming experience & 33.63 & 12.48 & & \\
\hline Number of barley plots & 2.21 & .77 & & \\
\hline Distance of plots & 56.78 & 30.18 & & \\
\hline Total expenditure & 1279.92 & 634.90 & & \\
\hline Livestock holding & 3.29 & 2.29 & & \\
\hline Amount of credit & 1775.61 & 1759.91 & & \\
\hline Distance to market & 5.31 & 2.35 & & \\
\hline Sex & & & 19.51 & 80.49 \\
\hline Crop rotation & & & 19.51 & 80.49 \\
\hline Soil fertility & & & 24.39 & 75.61 \\
\hline Non-farm income & & & 41.46 & 58.54 \\
\hline
\end{tabular}

\section{Results of Econometric Models}

\section{Hypothesis testing}

The first hypothesis was that selecting the appropriate functional form which fits to the data set by using likelihood ratio test. The most commonly functional forms reviewed in most previous researches were Cobb-Douglas and Trans-log. Then by applying the likelihood ratio test statistic which is $L R=-2[\operatorname{lr}(\operatorname{Cobb}-$ Douglas $)-\operatorname{lr}(\operatorname{Trans} \log )]$, the null hypothesis was rejected implies that the trans-log functional form adequately represented the data set. Table 3. Generalized likelihood ratio tests of hypothesis for the parameters of the SPF

\begin{tabular}{llllll}
\hline Null hypothesizes & LH0 & LH1 & $\begin{array}{l}\text { Calculated } \\
\text { value }\end{array}$ & $\begin{array}{l}\text { Critical value of } \\
\chi 2(0.05)\end{array}$ & Decision \\
\hline H0: $\beta \mathrm{ij}=\mathrm{O}$ & -84.25 & -70.43 & 27.64 & 24.99 & Reject H0 \\
H0: $\gamma=0$ & & & 0.63 & & Reject H0 \\
H0: $\delta 1=\delta 2=\ldots=\delta 13=0$ & -88.54 & -70.43 & 36.22 & 22.36 & Reject H0 \\
\hline
\end{tabular}

Source: Own computation (2017) 
The second hypothesis was conducted to decide whether the average production function without considering non-negative random error term best fits the data set or not. $\mathrm{H} 0=\gamma=0$ and $\mathrm{H} 1=\gamma>0$. The gamma $(\gamma)$ parameter is defined as the ratio of the unexplained inefficiency error term $\left(\delta u^{2}\right)$ to the total sum of errors $\left(\delta u^{2}+\delta v^{2}\right)$. Since, the value of gamma is $63 \%$ which indicated that there was technical inefficiency so, the traditional production function is not an adequate representation of barley production in this study.

Thirdly, the null hypotheses say that a model without explanatory variables of inefficiency effects while, the alternative hypothesis says the full frontier model with explanatory variables are supposed to determine inefficiency. Therefore, explanatory variables of technical inefficiency can together determine variation in production of barley output in the study area.

\section{Estimation of production function}

The dependent variable in estimation of stochastic production function was barley outputs produced in quintals analyzed on the five major inputs with their square and interaction terms. The major five inputs were land under barley, amount of barley seed, quantity of fertilizer, human labor and oxen power. The stochastic frontier model estimates both the trans-log functional forms of production function and variables of technical inefficiency simultaneously by using the first stage estimation approach.

As it presented in Table (3) looking from the output of the model below, seed had negative and significant effect on the output of barley at $5 \%$ level of significance. The negative effect was might be due to the reason that, the farmers use low quality local seed below the recommended rate $(120 \mathrm{~kg} / \mathrm{hectare})$ and they did not apply improved barley seed that improves the quantity of barley output in the study area. Fertilizer is one of the necessary inputs to improve barley output by maintaining soil fertility and it was significant at $5 \%$ level of significant. Hence, a farmer who increased the application of fertilizers in turn earns more output of barley. Labor had a positive sign and significantly affected barley output at $1 \%$ level of significance. In order to increase their barley output farmers must increase their family or hired labor for performing different farming operation on the field. In most developing countries like Ethiopia, oxen are the main source of draft power to perform 
activities like ploughing and sowing crops. In line to this, oxen power had a significant and positive effect on farmers barley output in the study area.

Table 4. Production function model

\begin{tabular}{ll}
\hline Ln output & Coefficient (Standard error) \\
\hline Ln of fertilizer & $0.313^{*}(0.156)$ \\
Ln of seed & $-0.48^{* *}(0.222)$ \\
Ln of labor & $0.436 * *(0.158)$ \\
Ln of oxen & $0.364 *(0.205)$ \\
Ln of land & $0.168(0.265)$ \\
Ln of fertilizer square & $-0.672(0.520)$ \\
Ln of seed square & $0.413(0.487)$ \\
Ln of labor square & $-0.185(0.540)$ \\
Ln of oxen square & $1.603 * * *(0.346)$ \\
Ln of land square & $-0.044(0.168)$ \\
Ln of fertilizer*seed & $2.011 * *(0.980)$ \\
Ln of fertilizer*labor & $-0.232(0.514)$ \\
Ln of fertilizer*oxen & $-0.827 *(0.490)$ \\
Ln of fertilizer*land & $0.095(0.242)$ \\
Ln of seed*labor & $-0.739(0.794)$ \\
Ln of seed*oxen & $-2.524 * * *(0.697)$ \\
Ln of seed*land & $-0.063(0.205)$ \\
Ln of labor*oxen & $1.173 *(0.645)$ \\
Ln of labor*land & $-0.190(0.125)$ \\
Ln of oxen*land & $-0.008(0.015)$ \\
Constant & $-1.32(2.25)$ \\
Gamma & 0.63 \\
Log likelihood & -70.43 \\
Lambda & 1.32 \\
\hline
\end{tabular}

\section{Technical efficiency score of barley producers}

The result of frontier model revealed that, the mean technical efficiency of the sample household farmers during the $2015 / 16$ production season was $70.9 \%$ and it ranged from $14 \%$ to $95 \%$. This indicated that, there is a wide gap variation among the sample barley producer farmers in the study area. It also told that, farmers could had more possibility to increase their current production of barely output on average by $29.1 \%$ without changing the existing inputs. In other word, farmers had an opportunities to decrease all the current input usage by $29.1 \%$ without decreasing the output of barley produced.

\section{Sources of inefficiency variation among barley producers}


The socio economic, farm related and institutional variables expected to affect technical inefficiency; education level, frequency of extension contact, the practice of crop rotation, number of barley plots, distance of home to the plot, total expenditure, soil fertility of land and distance to home from the nearest market were the significant variables that affected the technical inefficiency score of barley growing farmers in the study area.

Table 5. Source of technical inefficiency

Technical inefficiencies variables

Coefficient (S. error)

\begin{tabular}{ll}
\hline Farming experience & $-0.004(0.019)$ \\
Education Level & $-0.168 *(0.098)$ \\
Frequency of extension contact & $-0.124 *(0.074)$ \\
Number of barley plots & $-0.718 * *(0.33)$ \\
Crop rotation & $1.535 * *(0.65)$ \\
Non-farm income & $-0.351(0.58)$ \\
Livestock ownership & $-0.017(0.12)$ \\
Ln credit & $-0.008(0.02)$ \\
Distance to market & $0.191 *(0.10)$ \\
Ln expenditure & $1.984 * *(0.48)$ \\
Soil fertility & $-1.366 * *(0.55)$ \\
Distance to home & $1.277 *(0.57)$ \\
Sex & $-0.352(0.60)$ \\
Constant & $-9.540 * *(4.03)$ \\
\hline
\end{tabular}

Level of education: The education level of farmers had negative relation with technical inefficiency and significant at 10\% significance level. For every increment in education level by one years of schooling, the technical inefficiency of farmers would decreased by 0.168 scores. As a farmers becomes educated s/he has an awareness how to maximize their barley output with the given limited inputs.

Frequency of extension contact: As expected the coefficient was negative and significantly affected the level of technical inefficiency at $10 \%$ level of significance, respectively. This might be due to the reason that, the information that got from extension workers had a power to increase the awareness and know-how of farmers towards technologies and efficient utilization of the existing resource to decrease their inefficiency and wastage of resource use. 
As the extension workers frequently visit and follow up farmers more and more, farmers may obtained important and influential information to decrease their technical inefficiency level by 0.124 scores, ceteris paribus. This finding was in-line with (Jude et al., 2011; Mustefa, 2014).

Number of barley plots: On contrary to the expected sign it had negative relationship and significant at $5 \%$ for technical inefficiency. Other variables holding fixed, additional barley plot is associated with a decrement in technical inefficiency by a 0.718 score. It revealed that those farmers having barley farm plots more than one in different locations were more efficient. This might be due to the fact that, in the study area farmers cultivate barley by share-cropping system in addition to their own land. So, this enables them had more farm plots at different location and reduce inefficiencies associated with risks that come due to frost. In the study area, some plots locations are vulnerable for frost and others are not and it is a serious problem that aggravate their inefficiency of crop production. In addition, it might be due to difference in the soil fertility of barley farm plots at different location that is, on average fertile soils would help to earn higher output and improve efficiencies of farmers. This finding was consistent with the findings of (Tan et al., 2010; Yami et al., 2013); Wudineh and Endrias, 2016).

Crop rotation: Its coefficient was positive and significant at 5\% level of significance for technical inefficiency. As compared to those farmers who practice crop rotation, the technical inefficiency of not practicing crop rotation increased by 1.535 scores other factors fixed. Therefore, practicing crop rotation especially cereals with legume crops can restore and maintain soil fertility so as to decrease the technical inefficiency of barley producers by increasing its barley production. This finding was in line with (Musa, 2013).

Distance to the nearest market: As expected it affected technical inefficiency level positively and significantly at $10 \%$ level of probability. As the distance of the nearest market to the farmer's residence increased by one kilometer, the technical inefficiency of farmers also increased by 0.191 scores. This implies that as the farmers is far from market, their inefficiency increases because it incurs more cost to transport inputs and outputs, transaction costs and to get market information. The result was in line with (Hassen, 2011; Musa et al., 2015). 
Total expenditure of the household: The coefficient of total expenditure of the household had a positive sign and significant effect on technical inefficiency at $5 \%$ levels of probability. Holding other variables constant, if expenditure of household increased by $1 \%$ farmers technical inefficiency also increased by 0.02 scores. This might be due to the reason that, during the survey period majority of their income is spend for consumption purpose to feed their household and construction of houses. In turn, this causes cash deficiency to buy basic and required inputs to decrease their technical and economic inefficiencies. The result was in line with (Mustefa, 2014).

Soil fertility: It had a negative as well as a significant influence on technical inefficiency level at $5 \%$ levels of significance. It means that, as compared to those individuals having in fertile lands, the technical inefficiencies of farmers having fertile land had decreased by 1.36 scores, holding other factors constant. Therefore, such policies to increase and maintain soil fertility of land must had a negative effect on inefficiency of barley production. The result was similar with the findings of (Alemayehu, 2010; Musa, 2013); Hailemaraim, 2015).

Distance to home: The average distance between the plots and farmers residence positively affected the technical inefficiency of barley producers at $5 \%$ levels of significance. Ceteris paribus, additional average distance between residence of farmer and his/her barley plot is associated with an increment of 1.277 technical inefficiency scores of the farmer. The distance between farm and farmers residence strongly affect their frequency of supervision, plant protection and application organic fertilizer especially animal dung. Because, all these factors strongly increase his/her technical inefficiency level. The result was similar with the findings of (Alemayehu, 2010).

\section{CONCLUSIONS}

This study was conducted with the objectives of estimating the level of technical efficiency and identifying the sources of inefficiency variation among barley producers in Meket District, Amhara National Regional State of Ethiopia. The trans-log functional form of the production function revealed that, the mean technical efficiency of $70.9 \%$ and it ranging from the minimum of $14 \%$ to the maximum of $95 \%$. This figure told that, there is a possibility to increase the technical efficiency of barely producers on average by $29.1 \%$ with the existing resources on hand if appropriate measures are taken in resource use. The one stage estimation 
technique of frontier model also clearly revealed that education level, frequency of extension contact and number of barley plots affected technical inefficiency negatively. With the same fashion, the practice of crop rotation by farmers, distance of the farmer's residence from the nearest market, total expenditure of household, soil fertility and distance of the plot from home had positive effects on technical inefficiency variation among the barley producer farmers.

\section{Recommendations}

The main goal of this study was showing the degree of variation and identification of important variables that bring disparity of technical inefficiency among farmers. As expected, the result of the study clearly showed the presence of technical inefficiency variation among the farmers and identify which variables strongly affected their inefficiency level. It also showed that there is a huge opportunity to improve their efficiency level and increase barley output if appropriate measures are taken.

Firstly, the result of the study indicated that, frequency of extension contact of farmers with extension agents was the significant variable and had a negative effect on all inefficiencies level. This means that any policy aimed to improve the capacity of development agents will decrease the technical inefficiency of farmers. Since, development agents had a pivotal role to disseminate new production information, technologies and inputs from the research field to the actual farmers on ground. Therefore, special emphasis and motivation should be given for those personnel so as to improve the efficiency level. This is possible by upgrading the development agents or extension workers by providing practical attachment training with the current agricultural production and as much as possible decrease ratio of development agents to the number of farmers so as to increase the number of extension contact and to make the number of farmers manageable to the extension agents.

Secondly, the result confirmed that education level of the household calls a special emphasis to upgrade the managerial ability of farmers or farmer's education. This can be achieved by providing youth training center, practical training and creation of awareness and knowhow about the application of inputs and different farming system.

Thirdly, the result suggested that policy makers would significantly decrease the technical inefficiency of sample farmers via the development of road and market infrastructure that 
reduce home to market distance as well as home to farm plot. In addition, it is better to launching of new market around their residence exercising to purchase farm inputs and to sell their outputs with a minimum transaction cost.

\section{REFERENCES}

Abu Tefera and Teddy, T. 2014. GAIN (Global Agricultural Information Network) Report on assessments of commodity and trade issues made by USDA staff. Addis Ababa, Ethiopia. Report no. 1301.

Aigner, D.C., Lovell, K.C.A. and Schmidt, P. 1977. Formulation and estimation of stochastic frontier production functions models. Journal of Economics, 6: 21-37.

Alemayehu, E. 2010. Analysis of factors affecting the technical efficiency of coffee producers in Jimma zone: a stochastic frontier analysis. MSc Thesis, Adiss Ababa, Ethiopia.

Aung, N.M. 2012. Production and economic efficiency of earmers and Millers in Myanmar Rice Industry. Institute of Developing Economies, Japan External Trade Organization. V.R.F. Series No. 471.

Berhane, G., Paulos, Z., Tafere, K. and Tamru, S. 2011. Food grain consumption and calorie intake patterns in Ethiopia. IFPRI Ethiopia Strategy Support Program II (ESSP II) Working Paper, 23.

CSA (Central Statistics Agency). 2014. Annual Statistics Bulletin: Addis Ababa, Ethiopia.

CSA (Central Statistical Agency). 2016. Agricultural sample survey report on area, production and farm management practice of belg season crops for private peasant holdings, 5 .

FAO (Food and Agricultural Organization). 2014. Annual report. Addis Ababa, Ethiopia.

Hailemariam Leggesse. 2015. Technical efficiency in Teff production: The case of Bereh District, Oromia National Regional State. MSc Thesis, Haramaya University, Haramaya, Ethiopia.

Hassen Beshir, 2011. Performance of mixed crop-livestock production system: The data envelopment approach. Livestock Research for Rural Development. 23(200). 
Jude, C., Benjamen C. and Patrick C. 2011. Measurement and determinants of production efficiency among smallholder sweet potato farmers in Imo state, Nigeria. European Journal of Scientific Research, 59 (3): 307-317.

Musa Hasen, 2013. Economic efficiency of smallholder farmers maize production: The case of Arsi Negelle District of West Arsi Zone. MSc Thesis, Haramaya University, Haramaya, Ethiopia.

Musa H., Lemma, Z. and Endrias, G. 2015. Measuring technical, economic and allocative efficiency of maize production in subsistence farming: Evidence from the Central Rift Valley of Ethiopia. Applied Studies in Agribusiness and Commerce, 9 (3): 6374.

Mustefa Bati. 2014. Economic efficiency in barely production: The case of Chole district, East Arsi Zone, Oromia National Regional State, Ethiopia. MSc Thesis, Haramaya University, Haramaya, Ethiopia.

Shahidur Rashid, Gashaw T. Abate, Solomon Lemma, James Warner, Leulsegged Kasa and Nicholas Minot. 2015. The barley value chain in Ethiopia. REAP (Research for Ethiopias’ Agriculture Policy).

Tan, S., Heerink, N., Kuyvenhoven, A. and Qu, F., 2010. Impact of land fragmentation on rice producers' technical efficiency in South-East China. NJAS-Wageningen Journal of Life Sciences, 57 (2): 117-123.

Wudineh Getahun and Endrias Geta. 2016. Technical efficiency of smallholder wheat farmers: The case of Welmera district, Central Oromia, Ethiopia Journal of Development and Agricultural Economics, 8 (2): 39-51.

Yamane, Taro. 1967. Statistics: An Introductory Analysis, $2^{\text {nd }}$ Edition, New York.

Yami, M., Solomon, T., Begna, B., Fufa, F., Alemu, T. and Alemu, D. 2013. Sources of technical inefficiency of smallholder wheat farmers in selected water-logged areas of Ethiopia: A translog production function approach. Africa Jornal of Agricultural Research, 8 (29): 3930-3940. 